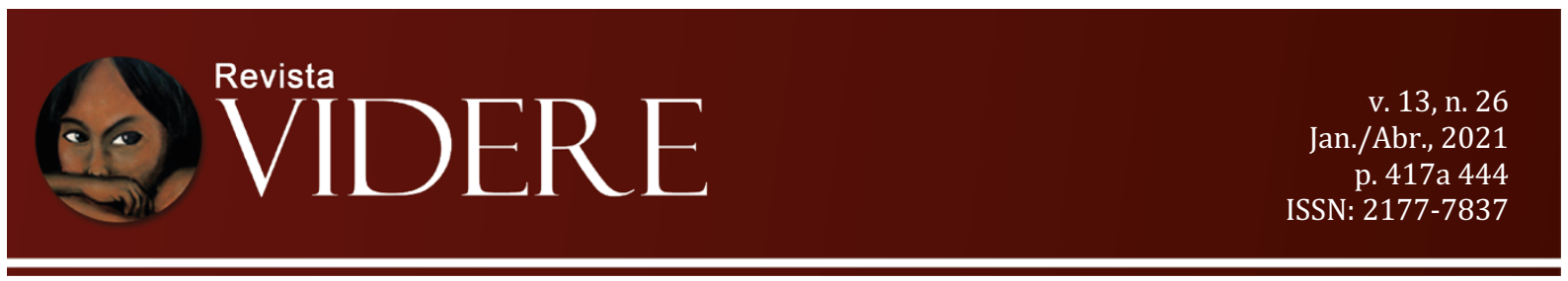

\title{
REFLEXOS DO RACISMO CAMUFLADO NA POLÍTICA MIGRATÓRIA BRASILEIRA E A INTERVENÇÃO JUDICIAL COMO ESPERANÇA EM OBTER O RECONHECIMENTO DA CONDIÇÃO DE REFUGIADOS
}

\author{
REFLECTIONS OF CAMOUFLAGED RACISM IN BRAZILIAN IMMIGRATION \\ POLICY AND JUDICIAL INTERVENTION AS A HOPE TO OBTAIN RECOGNITION \\ OF THE STATUS OF REFUGEES
}

\author{
REFLEXIONES DEL CAMUFLAJE RACISMO EN LA POLÍTICA MIGRATORIA \\ BRASILEÑA Y LA INTERVENCIÓN JUDICIAL COMO LA ESPERANZA DE \\ OBTENER EL RECONOCIMIENTO DE LA CONDICIÓN DE REFUGIADO
}

\author{
Alcindo Cardoso do Valle Junior \\ Mestre em Estudos Fronteiriços - UFMS \\ E-mail: alcindovallejr@gmail.com \\ OrcidID: 0000-0002-0486-8320
}

Gleicy Denise Vasques Moreira Doutora em Desenvolvimento Regional- UFMS

E-mail:gleicyvasques@gmail.com OrcidID: 0000-0003-4123-5810

Resumo: O presente artigo tem por escopo demonstrar o real descompasso entre a política migratória brasileira, ainda contaminada por décadas de práticas públicas racistas e preconceituosas, e a evolução legislativa que tutela as migrações, que ruma para a proteção dos direitos humanos fundamentais do migrante internacional que se encontra em território nacional. O método utilizado foi o hipotético dedutivo, com pesquisa documental e bibliográfica, além dos estudos exploratórios a partir do fluxo migratório ocorrido no período posterior à lei de migração n. 13.445/2017. Explora-se ainda que a intervenção judicial registrada em situação excepcional, motivada pela pandemia mundial do COVID-19, cria um precedente de esperança para os migrantes internacionais que lutam pelo reconhecimento da condição de refugiados com fundamento na Lei de Migração $n^{\circ} 9.474 / 97$, que passou a prever o reconhecimento da condição de refugiado em razão de grave e generalizada violação de direitos humanos.

Palavras-chave: Direitos humanos. migração. refúgio. políticas públicas. Covid-19.

Abstract: The scope of this article is to demonstrate the real mismatch between Brazilian immigration policy, which is still contaminated by decades of racist and prejudiced public 
practices, and the legislative evolution that protects migration, which moves towards the protection of the fundamental human rights of international migrants who found in national territory. The method used was the hypothetical deductive, with documentary and bibliographic research, in addition to exploratory studies from the migratory flow in the period after the migration law no. 13.445/2017. It is also explored that the judicial intervention recorded in an exceptional situation, motivated by the global pandemic of COVID-19, creates a precedent of hope for international migrants who are fighting for the recognition of the status of refugees based on the Migration Law $n^{\circ} 9.474 / 97$, which began to provide for recognition of refugee status due to a serious and widespread violation of human rights.

Keywords: Human rights. migration. refuge. public policy. Covid-19.

Resumen: El propósito de este artículo es demostrar el desajuste real entre la política migratoria brasileña, que aún está contaminada por décadas de prácticas públicas racistas y prejuiciosas, y la evolución legislativa que protege la migración, que avanza hacia la protección de los derechos humanos fundamentales de los migrantes internacionales que encontrados en territorio nacional. El método utilizado fue el hipotético deductivo, con investigación documental y bibliográfica, además de estudios exploratorios del flujo migratorio en el período posterior a la ley migratoria núm. 13.445/2017. También se explora que la intervención judicial registrada en una situación excepcional, motivada por la pandemia global de COVID-19, crea un precedente de esperanza para los migrantes internacionales que luchan por reconocer la condición de refugiados con base en la Ley de Migración $n^{\circ}$. 9.474/97, que comenzó a contemplar el reconocimiento de la condición de refugiado debido a una grave y generalizada violación de los derechos humanos.

Palabras clave: Derechos humanos. migración. refugio. políticas públicas. COVID-19.

\section{Introdução}

É inegável que a legislação brasileira que tutela as migrações internacionais evoluiu grandemente, em especial com a Constituição Federal de 1988 e, mais recentemente, com a nova Lei de Migração $n^{\circ} 13.445 / 2017$, estendendo de forma expressa as garantias individuais fundamentais aos migrantes internacionais que se encontrem em território brasileiro, entretanto, a história recente do Brasil registrou infaustos episódios de racismo nas práticas públicas que envolvem a política migratória, sendo seus possíveis reflexos nos dias atuais o objeto a ser explorado no presente artigo, adotando como base o caso dos imigrantes haitianos.

Prefacialmente, há que se registrar que o termo "refúgio" é popularmente utilizado no seu sentido amplo para caracterizar a simples condição de migrante internacional, independente das razões que motivaram a migração, enquanto que o instituto de natureza jurídica denominado refúgio, ou seja, em seu sentido estrito, é o que tem por fundamento a adesão formal do Brasil à Convenção de Genebra de 1951, relativa ao Estatuto dos Refugiados, e se configura nos casos em que a migração é motivada pelo fundado temor decorrente de perseguições de natureza 
política ou em casos de conflito armado, podendo abranger outras motivações definidas por tratados internacionais específicos.

Em 06 de abril de 2018 a Portaria Interministerial $n^{0}$ 10, a qual dispõe sobre a concessão de visto temporário e autorização de residência para fins de acolhida humanitária para cidadãos haitianos e apátridas, residentes no Haiti, passou a permitir a residência no Brasil pelo período de dois anos, com a possibilidade de conversão em residência por prazo indeterminado após tal período, porém tal visto somente poderia ser concedido na Capital do Haiti, Porto Príncipe, e de forma bem limitada e restrita.

Diante da grande dificuldade de obter o visto temporário, a atual situação dos migrantes haitianos que desde abril de 2018 intensificaram as migrações do Chile para o Brasil, tem sido tratada pela Polícia Federal como entrada excepcional, expedindo-se notificação na qual se concede prazo de 60 dias para regularização no país ou para, no mesmo prazo, deixar o país. Tal procedimento gera a permanência de grande número de migrantes haitianos em situação irregular no território nacional, dificultando o emprego, a inserção social e até mesmo o acesso à saúde básica.

A presente artigo tem como ponto de ignição as deficiências registradas no acolhimento, bem como no tratamento jurídico dispensado a migrantes haitianos no Brasil a partir da nova Lei de Migração, visto que se deparam com a escassez de políticas públicas específicas, impondo aqueles que não conseguem a documentação necessária para sua regularização, a busca com auxílio da Defensoria Pública da União do reconhecimento judicial da condição de refugiado, permeando o país em situação de grande vulnerabilidade, sobrevivendo na maioria das vezes de pequenas doações feitas por particulares, e pelo ganho obtido em pagamento de pequenos serviços, conhecidos como bicos, no mercado informal de trabalho.

O método a ser utilizado no trabalho será o hipotético dedutivo, com pesquisa documental e bibliográfica, além dos estudos exploratórios a partir do fluxo migratório de haitianos posterior à nova lei de migração n. 13.445/2017 (GIL, 1999). Como marco temporal será adotado o ano de 2018, tendo em vista o aumento considerável de pedidos de refúgio formulados por haitianos, e o corrente ano de 2020, considerando o relevante precedente judicial consistente na decisão liminar proferida pela Justiça Federal do Acre no Processo n. 1004501-35.2020.4.01.3000, cuja fundamentação e dispositivo final ratificou o espírito inclusivo da legislação brasileira que tutela as migrações internacionais frente à pandemia do COVID-19. 


\section{$2 \mathrm{O}$ instituto do refúgio para imigrantes haitianos}

Antes mesmo de explorar a evolução histórica do instituto do refúgio, merece atenção uma breve explicação a seu respeito. Com base no conceito estabelecido na Convenção de Genebra de 1951, assim como no Protocolo sobre o Estatuto dos Refugiados, pactuado em Nova York em 31 de janeiro de 1967, considerar-se-á refugiada qualquer pessoa que:

Temendo ser perseguido por motivo de raça, religião, nacionalidade, grupo social ou opiniões políticas, se encontra fora do país de sua nacionalidade e que não pode ou, em virtude desse temor, não quer valer-se da proteção desse país, ou que, se não tem nacionalidade e se encontra fora do país no qual tinha sua residência habitual, não pode ou , devido ao referido temor, não quer voltar a ele. (HATHAWAY, 1991, p. 9-10).

Portanto, o que caracteriza a situação de refúgio é a perseguição por cinco possíveis motivos: raça, religião, nacionalidade, pertencer a determinado grupo social, defender opiniões políticas ou, após a Declaração de Cartagena de 1984 e Lei de Migração nº 13.445/2017, enfrentar situações graves e generalizadas de violações de direitos humanos, como crises econômicas que causem extrema penúria à parcela da população (reconhecido para os imigrantes venezuelanos), somada à extraterritorialidade.

O reconhecimento da condição de refugiado no Brasil iniciou formalmente a partir de 1960, ano que marca a adesão do citado país à Convenção de Genebra de 1951 Relativa ao Estatuto dos Refugiados.

Dando sequência à evolução do reconhecimento dos direitos humanos fundamentais do refugiado, o então Presidente Emílio G. Médici promulgou através do Decreto $n^{\circ} 70.946$ de 7 de agosto de 1972 o Protocolo sobre o Estatuto dos Refugiados, pactuado em Nova York em 31 de janeiro de 1967.

Nesse contexto, Jubilut (2007, p. 171) explica:

O Brasil está comprometido com a normativa de proteção dos refugiados desde os primórdios da fase de universalização deste instituto, no início da década de 50 do século $\mathrm{XX}$, uma vez que ratificou e recepcionou tanto a Convenção de 51 quanto o Protocolo de 67, além de fazer parte do Conselho Executivo do ACNUR desde 1958.

Trinta anos depois, na toada do novel espírito de internacionalização dos direitos humanos dos refugiados, o Brasil aprovou a Lei no 9.474/1997, a qual regulamenta a aplicação do Estatuto do Refugiado e criou o Comitê Nacional para Refugiados - CONARE, órgão com autonomia e competência para analisar e conceder refúgio no Brasil, avançando definitivamente no cenário internacional como um dos países mais evoluídos no reconhecimento dos direitos 
fundamentais dos refugiados.

Não obstante a inegável evolução da legislação brasileira no que tange aos direitos dos refugiados, há que se registrar o vácuo legislativo existente mesmo no período republicano do Brasil, assim como o contexto real que motivou a elaboração do Estatuto do Estrangeiro - Lei $\mathrm{n}^{\circ}$ 6.815, de 19 de agosto de 1980, o qual entrou em vigor em 10 de dezembro de 1981, assinado pelo então Presidente João Figueiredo, em pleno regime de ditadura militar, tratando o imigrante como verdadeira ameaça à segurança nacional, o que será abordado a seguir.

É relevante registrar que, não obstante a Declaração de Cartagena de 1984 ter ampliado as hipóteses de refúgio, considerando como refugiadas as pessoas que tenham fugido dos seus países porque a sua vida, segurança ou liberdade tenham sido ameaçadas pela violência generalizada, agressão estrangeira, conflitos internos, violação maciça dos direitos humanos ou outras circunstâncias que tenham perturbado gravemente a ordem pública, e a Lei n ${ }^{\circ}$ 9.474/97 em seu art. $1^{\circ}$, inciso III passar a prever o reconhecimento da condição de refugiado com base na grave e generalizada violação de direitos humanos, o CONARE - Comitê Nacional para Refugiados, ainda não reconheceu administrativamente nenhum pedido de refúgio para imigrantes haitianos fundamentado em tal motivação.

Tal intransigência do CONARE, tem por fundamento o modelo eurocêntrico do século passado, conforme lecionam Chiaretti; Severo (2018, p. 32) interpretando o Estatuto dos Refugiados:

\begin{abstract}
Mas, apesar da possibilidade conferida pela legislação brasileira por meio do art. $1^{\circ}$, III, do Estatuto dos Refugiados, e de todo esforço interpretativo de organismos nacionais e internacionais de ampliação da definição de refugiado para alcançar situações mais contemporâneas de grave e generalizada violação de direitos humanos sem a necessidade de se restringir a contexto de conflitos armados (que remetem à clássica definição de refúgio, em que há presença do agente perseguidor), o CONARE ainda é relutante a qualquer abertura para a caracterização de grave e generalizada violação de direitos humanos como fundamento para o reconhecimento da condição de refugiado, mantendo a intepretação do instituto ancorada no modelo eurocêntrico do século passado.
\end{abstract}

\title{
30 racismo camuflado na política migratória brasileira
}

A política migratória brasileira no período republicano se constituiu com fundamento em leis e práticas públicas que foram precedidas por um histórico marcado pelo período colonial, diretamente influenciado pelos dogmas imperialistas eurocentristas impostos durante séculos por Portugal. 
Com o final da escravidão e diante da proclamação da república no final do século XIX, os cafeicultores paulistas passaram a buscar a mão de obra de imigrantes para suprir a grande demanda da produção de café. Entretanto, alguns desses imigrantes abriam divergências com seus empregadores e, em busca de direitos, com ideias anarquistas e socialistas já amplamente difundidas na Europa, o que deflagrou movimentação política da elite social brasileira no sentido de aprovar uma lei que permitisse a expulsão de imigrantes indesejáveis. (grifo intencional).

O primeiro projeto de Lei com tal intuito foi apresentado na Câmara dos Deputados em 1894 (Projeto de Lei n. 109-B), entretanto, apesar da aprovação pela Câmara dos Deputados, foi rejeitado no Senado Federal. O mesmo aconteceu com o Projeto de Lei n. 317-A em 1902.

No ano de 1906, o então Deputado Federal Adolfo Afonso da Silva Gordo, elaborou novo Projeto de Lei que foi aprovado nas duas Casas de Leis e posteriormente sancionado pelo Presidente Afonso Pena em janeiro de 1907, constituindo-se no Decreto n. 1.641 de 07 de janeiro de 1907.

O Decreto n. 1.641/1907 previa em seu art. $1^{\circ}$ que: "O estrangeiro que, por qualquer motivo, comprometer a segurança nacional ou a tranquilidade pública, pode ser expulso de parte ou de todo o território nacional.” (BRASIL, 1907, p.1).

O referido Decreto previa ainda que o ato de expulsão ficava a cargo do Ministro da Justiça e Negócios Interiores (MJNI), que podia ordenar, como medida de segurança, a detenção do imigrante até o momento da partida, que, por sua vez, deveria ocorrer no prazo de três a trinta dias.

Obviamente que a intenção da Lei de Expulsão de Estrangeiros era causar temor nos imigrantes que organizavam os movimentos anarquistas e socialistas em busca de melhores salários e garantias de direitos trabalhistas, pois poderiam ser a qualquer momento sumariamente expulsos do país sob o argumento de ter comprometido a segurança nacional ou a tranquilidade pública.

Não obstante ter sido sancionado o referido Decreto, a luta pelos direitos sociais trabalhistas prosseguiu e, em reação ao crescente número de movimentos grevistas registrados em 1912, o próprio deputado Adolfo Gordo propôs alterações no texto da Lei de Expulsão de Estrangeiros, com o objetivo de endurecer ainda mais o seu já xenófobo texto, surgindo o Decreto n. 2.741/1913. (grifo intencional).

$\mathrm{Na}$ sequência histórica brasileira, as políticas públicas para migrantes internacionais tomavam como norte a ideia de que estrangeiros somente eram desejáveis ao Brasil caso se submetessem à mão de obra no campo ou para o trabalho braçal nas poucas indústrias que 
surgiam, ou ainda como estivadores nos portos, sem insurgências para defesa de melhores condições de trabalho e direitos sociais.

Nesse diapasão, Carneiro (2010, p. 47-48) historia com base em documentos públicos da época:

\begin{abstract}
A partir de 1931, o aparelho do Estado procurou definir uma série de mecanismos inibidores dos movimentos imigratórios e dos conflitos sociais. Atento à mobilização de uma série de grupos estrangeiros que se organizavam politicamente nos subterrâneos da sociedade, o governo brasileiro procurou traçar um sistema de regras que impedisse a entrada maciça de imigrantes e, em especial, de judeus, suspeitos em potencial de práticas comunistas. Ao avaliarem os projetos de colonização, estariam não apenas selecionando o bom imigrante como também controlando o processo de ocupação do território nacional, acesso à terra, o abastecimento da mão de obra, o fluxo de riqueza no país. Enfim, estariam colocando em prática os ideais de justiça social por meio de uma política de proteção ao trabalhador nacional.
\end{abstract}

Durante o Estado Novo, a política brasileira para migrantes internacionais adotou um aspecto dúplice, internamente considerando o imigrante como ameaça, restringindo ao máximo a sua entrada, não se submetendo integralmente aos tratados internacionais vigentes, entretanto, para aparentar internacionalmente como um país acolhedor de imigrantes, manifestava interesse na defesa dos direitos humanos, incluindo-se aí os direitos humanos internacionais dos migrantes internacionais e refugiados.

Em minucioso estudo dos documentos públicos arquivados à época, Carneiro (2010) concluiu que a postura do governo Vargas, durante todo o Estado Novo, procurou sustentar no exterior uma imagem de nação soberana, com perfil de país humanitário e hospitaleiro, entretanto, a mentalidade que caracterizava a postura das autoridades integrantes do núcleo de poder se conduzia pelo autoritarismo anticomunista, antissemita e de censura às ideias políticas. (grifo intencional)

Nesse contexto, em outubro de 1933, a Liga das Nações, precursora da ONU Organização das Nações Unidas, concluiu em Genebra uma convenção internacional versando sobre a elaboração de um estatuto internacional sobre direitos dos refugiados, sendo o Brasil um dos países membros que deveria se pronunciar pela adesão ou não às intenções do referido instrumento internacional. $\mathrm{Na}$ esteira do que já demonstrava a tendência do governo Vargas e observando a possibilidade de poder aderir à convenção com reservas, o Brasil se pronunciou publicamente favorável à elaboração do estatuto internacional sobre direitos dos refugiados, porém invocando as ressalvas de manutenção do respeito às instituições, à segurança e a ordem pública de cada país. (grifo intencional).

Carneiro (2010, p. 70) expõe as razões para tais ressalvas: 
Em 25 de maio de 1937 - portanto antecipando o teor antissemita da Circular Secreta n. 1.127, de 7 de junho de 1937 - , o Ministério das Relações Exteriores expediu a Ordem de Serviço n. 25, com o intuito de 'impedir, quanto possível, a entrada no Brasil de imigrantes israelitas sem nacionalidade e, também, de apátridas'. Tal postura era justificada pelo fato de que estes (judeus), incluídos nas cotas de imigração dos países de onde procediam, estavam 'burlando' as disposições constitucionais pela impossibilidade de sua expulsão.

Sabia-se, com certeza, que judeus, negros e japoneses não se prestavam para a configuração do tipo étnico nacional, ainda que alguns intelectuais tivessem encontrado uma saída honrosa para a questão da mestiçagem brasileira. A entrada de imigrantes europeus brancos (não judeus) continuava a ser encarada como uma necessidade premente para alcançarmos a almejada purificação racial e ideológica.

A condução da política migratória brasileira se convertia de forma velada ao racismo, ratificado em atos das autoridades constituídas, na busca de uma purificação racial e ideológica, concebendo-se um perfil de imigrante ideal, ou seja, europeus brancos, não judeus.

Em 1938, entrou em vigor o Decreto-Lei n. 406 de 4 de maio de 1938, dispondo sobre a entrada de estrangeiros no território nacional, o qual estampava já no seu art. $1^{\mathrm{o}}$ a política de conveniência adotada pelo governo brasileiro, ficando claro que não convinha ao estado brasileiro a imigração de pessoas com enfermidades mentais, nervosas ou com moléstias infectocontagiosas graves, alcoólatras ou toxicômanos, aleijados, mutilados, inválidos, cegos, surdos-mudos, indigentes, vagabundos, ciganos e congêneres; elementos com antecedentes criminais ou que tivessem histórico de conduta nociva à ordem pública, à segurança nacional ou à estrutura das instituições.

Nesse ponto Carneiro (2010) deixa claro que oficialmente não havia qualquer referência expressa no texto legal a respeito de restrições a imigrantes judeus, porém o Itamaraty recomendava a observância da Circular Secreta n. 1.127, de conteúdo antissemita, conduta sempre justificada no fato de que a corrente migratória que interessava ao Brasil era a destinada à produção rural, sendo que os judeus, segundo o Ministério das Relações Exteriores, dificilmente se adaptavam ao trabalho no campo.

Para Koifman (2012), durante o Estado Novo, o Ministério da Justiça e Negócios Interiores concentrou funções e atribuições relacionadas a identificar, controlar, selecionar e restringir a entrada de estrangeiros no Brasil, sendo visível pela quantidade de decretos editados entre os anos 1938 e 1939, cerca de 20 tratavam de matéria relacionada à migração, todos com intuito muito claro de exercer o controle sobre os estrangeiros que já estavam no Brasil bem como os que futuramente migrassem para o país. Embora não fosse a conduta explícita e declarada do governo brasileiro, as posições fundadas em critérios supostamente étnicos, especialmente antissemita, ou fundadas em concepção própria da eugenia eram compartilhadas 
por uma gama considerável de funcionários do alto escalão do governo constituído, refletindo as convicções dos líderes da nação, no sentido de idealizar um perfil de imigrante ideal.

Assevera Carneiro (2010) que, mesmo após as atrocidades decorrentes do avanço da Alemanha nazista, e na contramão do que ocorria nos demais Estados aliados, o governo brasileiro não demonstrou empenho em auxiliar as vítimas do nazismo, a exemplo do confisco, por censura postal, de lista de refugiados enviada em novembro de 1.943 pela Sociedad de Protecion a los Inmigrantes Israelitas, com sede em Buenos Aires - Argentina, tendo a Polícia Federal brasileira interpretado como iniciativa perigosa, que poderia representar possível aceno para a imigração de grande quantidade de judeus com a intenção de reunião familiar.

Apesar do Brasil ter sido signatário da Convenção de Genebra de 1951 sobre o Estatuto dos Refugiados, no contexto pós $2^{\mathrm{a}}$ guerra mundial, bem como do Protocolo relativo ao Estatuto dos Refugiados de 1967, sua atuação no acolhimento de refugiados ente os anos 50 a 80 foi bastante acanhada se comparada a países como Estados Unidos e Argentina.

E somente na década de 1980 o Estatuto do Estrangeiro (Lei n ${ }^{\circ} 6.815 / 1980$ ) revogou o Decreto-Lei 406 de 4 de maio de 1938, suprimindo diversos preceitos preconceituosos e segregadores daquele Decreto-Lei, porém ainda no contexto de um governo militar, o espírito do novo Estatuto estava já declarado na sua própria denominação, tratando o estrangeiro com restrições impostas a quem representava possível ameaça à segurança nacional e à ordem pública.

A Constituição Federal de 1988, promulgada durante a vigência do Estatuto do Estrangeiro, trouxe em seus arts. $3^{\circ}, 4^{\circ}$ e $5^{\circ}$, garantias de direitos fundamentais para qualquer ser humano que esteja em território nacional, declarando no inciso II do art. $4^{\circ}$ que as relações internacionais reger-se-ão pelo princípio da prevalência dos direitos humanos. Merecem citação também os incisos VIII (repúdio ao terrorismo e racismo); IX (cooperação entre os povos para o progresso da humanidade); X (concessão de asilo político) e, parágrafo único (A República Federativa do Brasil buscará a integração econômica, política, social e cultural dos povos da América Latina, visando à formação -de uma comunidade latino-americana de nações), todos do mesmo art. $4^{\circ}$ da Carta Magna. Verifica-se claramente no texto constitucional a intenção do Brasil se tornar um país vanguardista no que tange à recepção de imigrantes internacionais, assim como de minimizar os efeitos das fronteiras físicas já estabelecidas na América Latina.

A distorção legislativa consolidada no Estatuto do Estrangeiro somente foi corrigida após transcorridas quase quatro décadas, com a aprovação da Nova Lei de Migração (Lei ${ }^{\circ}$ 13.445/2017) que revogou inteiramente o Estatuto do Estrangeiro (Lei n ${ }^{0} 6.815 / 1980$ ). A novel legislação entrou em vigor em novembro de 2017, reconhecendo a migração como um direito, 
com expressa vedação à xenofobia, ao racismo e a outras formas de discriminação, além de garantir aos migrantes o livre acesso à justiça, educação e saúde.

Desta forma, pode-se afirmar que a Nova Lei de Migração busca a estabilização definitiva da harmonia entre a Lei de Migração, a Constituição Federal e o Estatuto do Refugiado, registrando-se aqui a pendência da necessária regulamentação da nova lei, bem como a sedimentação da sua intepretação pelo judiciário brasileiro.

A evolução da internacionalização dos direitos humanos do refugiado passa necessariamente pela necessidade de incutir no ser humano o sentimento solidário de proteção incondicional da dignidade humana, sentimento este que parece somente aflorar em situações extremas, motivadas por genocídios, guerras ou práticas terroristas, quando, na realidade, deveria fazer parte do dia a dia e da formação do caráter de todo ser humano.

Nesse mesmo sentido, se mostra preciso e esclarecedor o raciocínio de Piovesan (2017, p. 73):

Ao longo da história as mais graves violações aos diretos humanos tiveram como fundamento a dicotomia do 'eu vs. o outro', em que a diversidade era captada como elemento para aniquilar direitos. Vale dizer, a diferença era visibilizada para conceber o "outro" como um ser menor em dignidade e direitos, ou, em situações limites, um ser esvaziado mesmo de qualquer dignidade, um ser descartável, um ser supérfluo, objeto de compra e venda (como na escravidão) ou de campos de extermínio (como no nazismo). Nesta direção, merecem destaque as violações da escravidão, do nazismo, do sexismo, do racismo, da homofobia, da xenofobia e de outra práticas de intolerância.

O tema refugiados ganhou proporções nos últimos anos, abrindo relevantes discussões na União Europeia e nas Américas, em situações motivadas pelo avanço do domínio territorial do grupo extremista conhecido como Estado Islâmico na Síria e no Iraque, ou pelo declínio econômico e perseguições políticas na Venezuela, Haiti e Bolívia, fatos que agregam maior valor humanitário à atual legislação vigente no Brasil. (grifo intencional).

Mesmo com os avanços da legislação brasileira nesse campo, a situação de vulnerabilidade e a precariedade da condição jurídica dos migrantes internacionais está longe de acabar, e seria até mesmo utópico imaginar que o refúgio repentino em país estrangeiro representaria a solução imediata para todos os problemas vivenciados pelo migrante. Como inicialmente se expôs, a política migratória atual, mesmo diante das situações traumáticas vivenciadas pelo migrante no seu país de origem, fazendo que o mesmo deixe para trás sua profissão, bens, família, etc, mantém restrições inexplicáveis, em total descompasso com a própria legislação vigente, o que justificará a abordagem do ativismo judicial como ponto de equilíbrio para resguardar os direitos dos migrantes internacionais em estado de 
vulnerabilidade.

\section{A internacionalização dos direitos humanos}

Por sua própria natureza, os direitos humanos são internacionais, haja vista que não existe qualquer fronteira que possa elidir ou distinguir os direitos fundamentais de todo ser humano, entretanto há que se registrar as diversas formas de tratamento formal desse ramo do direito, através de tratados e convenções internacionais e por legislação interna com jurisdição restrita aos respectivos países soberanos.

Conforme defende Bobbio (1992, p. 5):

[...] os direitos do Homem, por mais fundamentais que sejam, são direitos históricos, ou seja, nascidos em certas circunstâncias, caracterizadas por lutas em defesa de novas liberdades contra velhos poderes, e nascidos de modo gradual, não todos de uma vez e nem todos de uma vez por todas.

A internacionalização dos direitos humanos é fenômeno abissalmente recente, iniciado após a segunda guerra mundial, em clara reação às condutas desumanas vivenciadas durante o período do domínio nazista na Alemanha. Via de regra, toda legislação de natureza garantista surge como reação às situações extremas, sofrimentos, traumas coletivos, assim como ocorreu com a legislação trabalhista que se desenvolveu em reação aos abusos ocorridos após a revolução industrial, a legislação humanista representa uma intensa reação aos horrores já experimentados pela humanidade, em especial durante a segunda guerra mundial.

Nesse contexto, o pós-guerra era o ambiente profícuo para o desenvolvimento de teses garantistas dos direitos fundamentais do ser humano, independentemente de raça, cor, língua, nacionalidade, religião, condição financeira, posicionamento político, etc, fazendo surgir da Organização das Nações Unidas, criada em 1945, sendo que em 10 de dezembro de 1948 foi proclamada por ato da Assembleia Geral da Organização das Nações Unidas a Declaração Universal dos Direitos Humanos, o marco definitivo da universalização da proteção dos direitos fundamentais do ser humano.

A partir da Declaração Universal dos Direitos Humanos, diversos instrumentos internacionais passaram a tratar especificamente de grupos historicamente castigados por tratamentos abusivos e traumáticos, fazendo surgir tratados visando a proteção de pessoas com deficiência, crianças, mulheres, índios, comunidades tradicionais, entre outros.

Nessa senda, diversos países harmonizaram sua legislação interna com a legislação internacional já produzida, consolidando internamente os conceitos garantistas da Declaração 
Universal dos Direitos Humanos, além de produzir instrumentos internacionais de proteção aplicáveis regionalmente.

Neste sentido:

A estrutura normativa de proteção internacional dos direitos humanos, contudo, além dos instrumentos de proteção global, de que são exemplos, dentre outros, a Declaração Universal dos Direitos Humanos, o Pacto Internacional sobre Direitos Civis e Políticos e o Pacto Internacional dos Direitos Econômicos, Sociais e Culturais, e cujo código base é a chamada International Bill oh Human Rights, abrange, também, os instrumentos de proteção regional, aqueles pertencentes aos sistemas europeu, americano e africano (v.g. no sistema americano, a Convenção Americana sobre Direitos Humanos). Da mesma forma que ocorre com o sistema de proteção global, aqui também se encontram instrumentos de alcance geral e instrumentos de alcance específico. Gerais são aqueles que alcançam todas as pessoas, a exemplo dos tratados acima citados; específicos, ao contrário, são os que visam apenas determinados sujeitos de direito, ou determinada categoria de pessoas, ao exemplo das convenções de proteção às crianças, aos idosos, grupos etnicos minoritários, às mulheres, aos refugiados, às pessoas com deficiência, etc.(MAZZUOLi, 2018, p. 763).

$\mathrm{Na}$ visão de Comparato (2007), o reconhecimento oficial dos direitos humanos pela autoridade política competente, em especial amparado pela legislação interna do país, proporciona muito mais segurança às relações sociais, exercendo também função pedagógica no seio da comunidade, no sentido de fazer prevalecer os grandes valores éticos, os quais, sem esse reconhecimento oficial, tardariam a se impor na vida coletiva.

Com a evolução da proteção dos direitos fundamentais do ser humano, naturalmente foi transferido para o Estado o dever de garantir a dignidade mínima da pessoa humana, traduzindo-se em princípios constitucionais basilares, como bem enfatizou Martins (2019, p. 1.600) na exegese da Constituição Federal vigente:

Dessa maneira, é homogêneo na doutrina, nacional e internacional, o entendimento de que decorre da dignidade da pessoa humana o de ver estatal de garantir a todos um mínimo existencial dos direitos sociais, sem os quais se viola a integralidade da natureza humana. Nas palavras de Daniel Sarmento, 'tal ideia provém não apenas da positivação dos direitos sociais no texto constitucional, como também da consagração do princípio da dignidade da pessoa humana como fundamento do Estado e da ordem jurídica brasileira'.

Segundo Mazzuoli (2018), são características dos direitos humanos contemporâneos: historicidade, universalidade, essencialidade, irrenunciabilidade, inalienabilidade, inexauribilidade, imprescritibilidade, vedação do retrocesso, entre outros.

Resumidamente, na concepção de Mazzuoli (2018), a historicidade se traduz no fato dos direitos humanos serem históricos, ou seja, foram constituídos em reação a fatos históricos que assombraram a humanidade; a universalidade, por sua vez, corresponde à internacionalização dos direitos humanos, sendo titulares de sua tutela todos os seres humanos, independentemente de raça, religião, idade, nacionalidade, poder econômico, posição política, 
etc; a essencialidade, é justificada pelo se tratarem de direitos supremos do ser humano, que fazem parte da sua própria essência, devendo sempre prevalecer a dignidade humana sobre qualquer outra circunstância.

A irrenunciabilidade é característica decorrente da sua indisponibilidade, ou seja, a proteção da dignidade humana é bem que deve ser protegido mais que a própria vontade do indivíduo, de forma que o mesmo não pode renunciar à própria dignidade peculiar à condição humana; a inalienabilidade consiste na impossibilidade de tais direitos serem cedidos ou transferidos, gratuita ou onerosamente, reforçando a regra de que são indisponíveis e inegociáveis; a inexauribilidade, traduz a ideia de que os direitos humanos podem sempre ser ampliados e complementados.

E, por fim, a imprescritibilidade é a característica que impede os direitos humanos de serem atingidos pela prescrição, de forma que podem ser exercitados a qualquer tempo; a violação do retrocesso, como já mencionado, é a impossibilidade de retroceder à condição prejudicial às garantias fundamentais já conquistadas pelo ser humano, devendo sempre prevalecer a condição mais benéfica.

Em todas as suas características, os direitos humanos expressam a importância de consolidar direitos fundamentais básicos para todos os seres humanos em qualquer circunstância ou localização no globo terrestre, entretanto as violações aos direitos humanos dos refugiados são frequentes e merecem um estudo mais aprofundado.

\section{Admissão do migrante internacional no território nacional após a lei 13.445/2017}

A nova Lei de Migração (lei 13.445/2017) trouxe uma nova realidade legislativa aplicável ao migrante internacional, antes tutelado pelo Estatuto do Estrangeiro, Lei 6.815/1980, a qual tratava o estrangeiro como verdadeira ameaça à soberania e à segurança nacional. Com o advento da nova Lei de Migração, o Brasil passou a ter uma das mais vanguardistas e garantistas legislação sobre migração.

Independente da abertura concedida por força da nova Lei de Migração, Mazzuoli (2018, p. 648) pondera:

É princípio correntemente aceito em Direito Internacional que um Estado não é obrigado aceitar, em seu território, o ingresso de estrangeiros, quer a título provisório ou permanente. Nesse sentido, o Institutde Droit Internacional, na sua sessão de Genebra de 1982, no estabelecimento das 'Regras Internacionais sobre Admissão e Expulsão dos Estrangeiros', de que foram relatores Féraud Giraud e Ludwig von Bar, deixou claro que, 'para cada Estado, o direito de 
admitir ou não estrangeiros em seu território, ou de admiti-lo apenas condicionalmente, ou de expulsa-lo, é uma consequência lógica e necessária da sua soberania e de sua independência'. Portanto, o princípio ora em análise, ainda tradicionalmente utilizado, é o da plena liberdade do Estado em matéria de admissão de estrangeiros, salvo (evidentemente) se houver obrigação convencional em sentido contrário.

No Brasil, uma vez satisfeitas as condições impostas na Lei 13.445/2017, em tempo de paz, qualquer estrangeiro pode ingressar e permanecer em território nacional, sendo também livre para deixar o país.

Por força do art. 38 da citada Lei, caberá à Polícia Federal a competência para exercer as funções de polícia marítima, aeroportuária e de fronteira, nos pontos de entrada e saída do território nacional.

Art. 38. As funções de polícia marítima, aeroportuária e de fronteira serão realizadas pela Polícia Federal nos pontos de entrada e de saída do território nacional.

Parágrafo único. É dispensável a fiscalização de passageiro, tripulante e estafe de navio em passagem inocente, exceto quando houver necessidade de descida de pessoa a terra ou de subida a bordo do navio. (BRASIL, 2017).

Nos termos do art. 12 da Lei de Migração, ao migrante internacional poderá ser concedido visto de visita, temporário, diplomático, oficial ou de cortesia, como permissão de ingresso em território nacional.

O visto de visita poderá ser concedido ao migrante internacional que tenha por intenção a estada de curta duração, não pretendendo fixar residência no país; o visto temporário, por sua vez, poderá ser concedido ao migrante internacional que tenha intenção de estabelecer residência temporária no Brasil, observadas as hipóteses do art. 14 da mesma lei; o visto diplomático e o oficial poderão ser concedidos à autoridades e funcionários estrangeiros que pretenderem adentrar ao território nacional para missão de caráter transitório ou permanente, na forma prescrita no art. 16 da Lei de Migração; e, por fim, o visto de cortesia poderá ser concedido a personalidades e autoridades estrangeiras em viagem não oficial ao Brasil; companheiros (as), independentemente de sexo, dependentes e outros familiares que não se beneficiem de Visto Diplomático ou Oficial por reunião familiar; trabalhadores domésticos de Missão estrangeira sediada no Brasil ou do Ministério das Relações Exteriores; artistas e desportistas estrangeiros que viajem ao Brasil para evento de caráter gratuito e eminentemente cultural.

Caso o migrante internacional ingresse em território nacional sem o respectivo visto, poderá ser autorizada a sua admissão de forma excepcional nos termos do art. 40 da Lei de Migração: 
Art. 40. Poderá ser autorizada a admissão excepcional no País de pessoa que se encontre em uma das seguintes condições, desde que esteja de posse de documento de viagem válido:

I - não possua visto;

II - seja titular de visto emitido com erro ou omissão;

III - tenha perdido a condição de residente por ter permanecido ausente do País na forma especificada em regulamento e detenha as condições objetivas para a concessão de nova autorização de residência;

IV - (VETADO); ou

V - seja criança ou adolescente desacompanhado de responsável legal e sem autorização expressa para viajar desacompanhado, independentemente do documento de viagem que portar, hipótese em que haverá imediato encaminhamento ao Conselho Tutelar ou, em caso de necessidade, a instituição indicada pela autoridade competente.

Parágrafo único. Regulamento poderá dispor sobre outras hipóteses excepcionais de admissão, observados os princípios e as diretrizes desta Lei. (BRASIL, 2017).

Consoante já fora exposto, os migrantes haitianos que adentram o país atualmente, estão sendo admitidos na condição de admissão excepcional, ocasião em que são notificados para dentro do prazo de 60 dias procederem a regularização de sua condição jurídica no Brasil ou, caso não promova a regularização, que deixe voluntariamente o país.

Cabe registro que, além das formas de visto de ingresso previstas no art. 12 da Lei de Migração, destacam-se outras relevantes conquistas no campo garantista de direitos humanos do migrante internacional, como a autorização de residência prevista no art. 30 da citada lei e regulamentada pelos arts. 123 a 163 do Decreto 9.199/2017 e a reunião familiar, que também pode motivar a concessão de visto ou autorização de residência nas hipóteses previstas no art. 37 da Lei de Migração.

\section{A relevância do poder de iniciativa do poder executivo e os efeitos da sua omissão}

O desenvolvimento de políticas públicas deve primordialmente ser da iniciativa do Poder Executivo, observando-se o ciclo regular de planejamento e previsão orçamentária.

O Estado é o grande protagonista na realização de políticas públicas, seja em razão da aprovação de lei que preveja diretrizes para a implantação de políticas públicas, seja pela identificação de um problema público que exija imediata solução por parte da administração pública municipal, estadual ou federal, seja pela decisão judicial que determina a realização de uma política pública face a omissão do respectivo gestor.

Sendo assim, o poder de iniciativa na execução de políticas públicas deverá ser sempre do Poder Executivo, observando sua capacidade orçamentária e o planejamento adequado conforme o regular ciclo de desenvolvimento de políticas públicas. 
Há que se ressaltar, entretanto, que as possíveis omissões da administração pública não podem ser enquadradas como políticas públicas, e merecem ser interpretadas como verdadeira ausência de política pública, quando o gestor se omite a sanar um problema público.

Nesse ponto, mister destacar que a previsão legal de implementação de uma política pública de natureza social constitui um patrimônio jurídico da cidadania que não pode mais ser desconstituído, não podendo o gestor público deixar de atender ao comando legislativo, sob pena de configurar retrocesso social.

Para Barroso (2003), a lei ao regulamentar um dispositivo constitucional, institui determinado direito que se incorpora ao patrimônio jurídico da cidadania e não pode ser absolutamente suprimido. Pretende-se, com a proibição do retrocesso, que seja mantido o nível de proteção social já consagrado, preservando as conquistas de modo a impedir a frustração da efetividade constitucional.

Nesses pontos de omissão do gestor público é que possibilitará a busca da proteção dos interesses difusos e coletivos, seja pela Defensoria Pública da União, pelo Ministério Público Federal ou através de Ação Popular, cabendo ao Poder Judiciário modular tal atuação, de forma a preservar as esferas de competência constitucionalmente estabelecidas para cada um dos poderes e ao mesmo tempo, garantir a fiel aplicação da legislação vigente e, acima de tudo, a preservação da dignidade humana.

\section{O princípio da separação dos poderes e o papel do poder judiciário}

Não obstante todas as necessidades coletivas identificadas na atuação do Estado frente às migrações internacionais, há que ser preservado o princípio constitucional da Separação dos Poderes, como base do equilíbrio do Estado e ordem jurídica brasileira.

Os entes federativos já estão sujeitos à fiscalização em todas as esferas de governo, seja por conta da aplicação da lei de responsabilidade fiscal ou mesmo pela observância da lei de improbidade administrativa. Desta forma, na administração de problemas públicos, a acepção do "poder-dever" é preponderante, e os entes estatais devem observar de maneira incondicional os mandamentos da lei. Mesmo porque tal assertiva está disposta no caput do artigo 37 da Constituição Federal de 1988 e é repetida em quase todas as Constituições Estaduais e Leis Orgânicas Municipais vigentes.

Sendo assim, todos os pontos, prioritários ou não, definidos por Lei para efeito da aplicação da verba pública são acertados por decisão discricionária da Administração e aprovada pelo poder Legislativo (ou seja, referendada pelos representantes do povo), definindo- 
se assim o orçamento anual, que deve ser respeitado com rigor, sob pena de submeter os cidadãos à privações de direitos.

Nesse rumo, qualquer ingerência em tais atos administrativos discricionários implica, em última análise, em ofensa ao princípio da Separação dos Poderes, princípio este basilar do Estado Democrático de Direito (artigo $2^{\circ}$ da Constituição Federal de 1988).

Portanto as decisões judiciais provocadas por incontáveis ações civis públicas ou ações populares, não raramente afrontam a autonomia estatal e o princípio da separação dos poderes, pois cabe ao Poder Judiciário prestar a tutela jurisdicional sem extrapolar os limites constitucionalmente estabelecidos para cada esfera de Poder. Tais decisões judiciais representam verdadeiras intervenções do Poder Judiciário na administração pública, correspondente à esfera de competência específica do Poder Executivo, muitas vezes causando severos desequilíbrios orçamentários ao ente público acionado, podendo ainda causar conflitos severos nas regiões de fronteira.

Assevera Carvalho Filho (2018) que existe um controle político, aquele que tem por base a necessidade de equilíbrio entre os Poderes estruturais da República, o Executivo, o Legislativo e o Judiciário. Nesse controle, cujo delineamento se encontra na Constituição Federal, pontifica o sistema de freios e contrapesos, nele se estabelecendo normas que inibem o crescimento de qualquer um deles em detrimento do outro e que permitem a compensação de eventuais pontos de debilidade de um para não deixá-lo sucumbir à força dos outros, ou seja, a busca do ponto de equilíbrio entre os poderes constituídos pela ordem jurídica nacional.

Portanto, a perda do equilíbrio entre os poderes da república pode gerar nefastos efeitos à população, devendo a busca de tal equilíbrio ser o norte para a excepcionalidade de medidas interventivas representadas por decisões judiciais no desenvolvimento e execução de políticas públicas.

Na visão de Secchi (2010), os juízes são servidores públicos que desempenham importante papel no processo de implementação de políticas públicas, pois cabe aos mesmos a prerrogativa de interpretar a justa ou injusta aplicação de uma lei por parte dos cidadãos e da própria administração pública.

Sendo assim, cabe ao Poder Judiciário a relevante missão de filtrar toda e qualquer atividade exagerada de provocação da atividade jurisdicional, analisando criteriosamente todas as possíveis medidas judiciais, e decidindo em liminares e sentenças de mérito a correção ou não da excepcional intervenção pretendida na gestão administrativa de competência constitucional atribuída ao Poder Executivo.

Ainda quanto ao impacto das decisões judiciais no desenvolvimento das políticas 
públicas, Secchi (2010) leciona que nos países onde vigora o sistema de Common Law, como Inglaterra e Estados Unidos, grande parte dos problemas de implementação de políticas públicas é decidida nos tribunais, já que nesse sistema há menor detalhamento da norma legal e ênfase muito maior na interpretação direta aos casos concretos. Enquanto nos países onde vigora o sistema do Civil Law, como Brasil e Itália, há uma ênfase maior no detalhamento da legislação com o intuito de diminuir a margem de interpretação da norma na aplicação aos casos concretos.

No Brasil, ainda que sob a égide do sistema do Civil Law, observa-se a ampla e relevante participação do poder Judiciário na análise e interpretação da lei aos casos concretos que envolvem as políticas públicas, seja na apreciação concentrada da interpretação das leis constitucionais pela corte constitucional (Supremo Tribunal Federal - STF), seja na interpretação das normas infraconstitucionais (Superior Tribunal de Justiça - STJ), seja na interpretação difusa da aplicação da norma realizada pelos juízos singulares e tribunais em segundo grau de jurisdição, repetindo-se que tal função se torna mais relevante ainda em função de filtragem das medidas judiciais promovidas em face de entes públicos e seus respectivos gestores.

Carvalho Filho (2018) leciona que a função administrativa é aquela exercida pelo Estado ou por seus delegados, subjacentemente à ordem constitucional e legal, sob o regime de direito público, com vistas a alcançar os fins colimados pela ordem jurídica.

Ainda quanto ao desenvolvimento de políticas públicas, Secchi (2010) assevera que estão cada vez mais evidentes as mudanças no papel do Estado moderno e o rompimento das barreiras entre esferas estatais e não estatais na solução de problemas coletivos, tais como o tráfico internacional de pessoas, a fome, a política de migração, o combate às doenças, entre outras. Sendo assim, uma pluralidade de atores protagoniza o enfrentamento dos problemas públicos.

Nesse esquadro, configura-se a recente situação ocorrida no primeiro semestre de 2018, que envolveu o acolhimento de imigrantes venezuelanos na cidade de Pacaraima-RO e dos imigrantes haitianos na cidade de Corumbá-MS, que geraram episódios de flagrante violações de direitos humanos amplamente noticiados nacionalmente e internacionalmente, ocasiões em que a sociedade civil, defrontando-se com o desaparelhamento estatal, prestou grande auxílio no atendimento e acolhimento temporário dos citados imigrantes, que em sua maioria se encontrava em situação de extrema vulnerabilidade. Muito embora o direito à saúde e assistência social estejam encartados na carta magna, os entes públicos envolvidos nos episódios acima relatados, se mostraram despreparados para um fluxo tão intenso de imigrantes 
adentrando o país.

Diante do flagrante desamparo, e das condições indignas que tais imigrantes se aglomeravam nas referidas cidades, cidadãos comuns, igrejas, empresários e ONGs, assumiram o relevante papel de proporcionar condições mínimas de acolhimento, higiene e saúde, abrindo suas casas e estabelecimentos para acomodar temporariamente tais vulneráveis.

Em resposta à omissão da administração pública em atender e acolher tais imigrantes em situação vulnerável, e, em atenção à farta legislação que os ampara e os garante o mesmo tratamento que qualquer cidadão brasileiro, a Defensoria Pública da União e o Ministério Público Federal expediram recomendações para que os respectivos gestores públicos dessem o adequado atendimento e acolhimento aos imigrantes haitianos e venezuelanos, respectivamente, providenciando todas as medidas necessárias a proporcionar aparelhos públicos que promovessem o atendimento e acolhimento dos mesmos.

Tal interferência retira completamente o poder de gestão do Executivo, e determina o atendimento imediato de uma crise na forma idealizada pelo Ministério Público e sujeita apenas ao filtro do poder judiciário, sem a necessária avaliação geral da saúde financeira do ente público e sem observância do regular ciclo de desenvolvimento de políticas públicas. Em analogia ao corpo humano, seria o mesmo que direcionar todo o sangue para o coração, deixando o cérebro sem irrigação sanguínea, o que por certo causaria a falência dos demais órgãos vitais.

A exemplo do que ocorreu em Corumbá-MS, cidade de fronteira com a Bolívia, o grande fluxo de imigrantes haitianos no primeiro semestre de 2018, não se repetiu nos meses subsequentes, de forma que, se o município tivesse atendido a recomendação ministerial no sentido de implantar um centro de atendimento e acolhimento ao imigrante de acordo com a demanda efêmera registrada no primeiro semestre do ano, certamente representaria um gasto imprevisto, que desiquilibraria o orçamento anual municipal e que se mostraria absolutamente desnecessário nos meses seguintes, haja vista que a passagem de imigrantes pela cidade retornou à normalidade.

Deve-se levar em conta que a criação de aparelhos públicos, ainda que em situações de anormalidade, como a ocorrida em Corumbá, devem ser estudadas com o máximo de cautela, pois o custeio com a manutenção de tais aparelhos públicos torna o Estado cada vez mais pesado e insustentável.

Destarte, algumas lições devem ser absorvidas para o desenvolvimento e execução de políticas públicas, devendo ficar primordialmente a cargo do Poder Executivo, que por sua vez tem o dever de observar o seu regular ciclo básico (1-identificação do problema; 2-formação 
da agenda; 3-formulação de alternativas; 4-tomada de decisão; 5-implementação; 6-avaliação; 7-extinção), sem excessivas interferências de ordens judiciais, sob pena de restar caracterizada ofensa ao princípio basilar constitucional da separação dos poderes, ficando reservadas tais intervenções para situações excepcionalíssimas, e ainda assim observados os limites orçamentários previamente definidos pelo Poderes Executivo com a devida chancela do Poder Legislativo.

\section{Decisão judicial paradigma - excepcionalidade que representa esperança para os migrantes internacionais vulneráveis em situação irregular no país}

Como já exposto, a tutela relativa aos direitos humanos é fundamentada em normas de regulamentação internacional (natureza global) e normas de natureza interna que devem se harmonizar na promoção da proteção dos direitos fundamentais do ser humano.

A regulamentação internacional do refúgio é orientada pela Convenção de Genebra de 1951 e seu respectivo Protocolo de 1967, dos quais se extrai o conceito internacional de refugiado, que, nas palavras de Hathaway(1991), se trata de indivíduo que, temendo ser perseguido por motivo de raça, religião, nacionalidade, grupo social ou opiniões políticas, se encontra fora do país de sua nacionalidade e que não pode ou, em virtude desse temor, não quer valer-se da proteção desse país, ou que, se não tem nacionalidade e se encontra fora do país no qual tinha sua residência habitual, não pode ou, devido ao referido temor, não quer voltar a ele.

Há que se registrar que, antes mesmo da Convenção de Genebra de 1951 sobre refugiados, foi dado importante passo para avançar na proteção dos direitos humanos dos refugiados, sendo criada em 3 de dezembro de 1949 o Alto Comissariado das Nações Unidas para os Refugiados (ACNUR), sendo seu Estatuto aprovado em dezembro do ano seguinte.

Segundo Guerra (2017), a função básica do Alto Comissariado das Nações Unidas para os Refugiados - ACNUR, cuja sede é em Genebra na Suíça, é a de dar proteção aos refugiados, isto é, para as pessoas que não podem gozar de proteção em seus países de origem. Assim, o ACNUR trabalha no sentido de garantir a permanência do indivíduo em determinado Estado (proibição de repatriação forçada) com a obtenção de um status favorável no país em que foram recebidos, bem como procura assistir os refugiados em termos materiais até que possam ter condições de mantença no Estrado que os abrigou.

Mais recentemente, em 19 de setembro de 2016, a Assembleia Geral da Organização das Nações Unidas - ONU adotou a Declaração de Nova York para os Refugiados e os Migrantes com o intuito de atualizar as regras internacionais de proteção ao refugiado e aos 
migrantes internacionais.

Quanto a regulamentação interna, há que se ressaltar que o Brasil é um dos poucos países que possui legislação específica a tutelar o instituto refúgio, que é a Lei nº 9.474/1997, a qual regulamenta internamente a aplicação do estatuído na Convenção de Genebra de 1951 e prevê os requisitos específicos para que seja reconhecida a condição de refugiado ao migrante internacional que solicita refúgio no país.

A citada Lei nacional, além de estar na vanguarda do reconhecimento dos direitos humanos do refugiado definido pela norma global, indicou textualmente em seu art. 48 a Declaração Universal dos Direitos Humanos de 1948 como seu referencial ético para a sua interpretação e aplicação aos casos concretos.

Ressalte-se ainda que a referida Lei criou o CONARE - Comitê Nacional para os Refugiados, passando a designar tal órgão como o competente para a análise dos pedidos de refúgio, cabendo-lhe ainda deliberar a respeito de possível cassação de ofício ou a requerimento de autoridade competente a concessão do refúgio. Compete ainda ao CONARE - Comitê Nacional para os Refugiados orientar e coordenar as ações voltadas à proteção dos refugiados, sua assistência, integração local, e apoio jurídico que se fizer necessário.

$\mathrm{Na}$ reprodução parcial do item $\mathrm{n}^{\mathrm{o}} 10$ do formulário de pedido de refúgio, pode ser verificada a complexidade das informações exigidas no preenchimento do citado formulário a ser submetido ao CONARE, sendo que a principal pergunta a ser respondida pelo solicitante de refúgio:

10- CIRCUNSTÂNCIAS DA SOLICITAÇÃO - Por favor, explique as razões pelas quais você decidiu deixar seu país de origem ou residência habitual e buscar proteção como refugiado no Brasil. Dê explicações detalhadas, descrevendo qualquer acontecimento, experiência pessoal ou medidas adotadas contra você ou membros de sua família que o (a) levaram a abandonar seu país de origem ou residência habitual. Se possuir provas de suas alegações, favor anexá-las. Se necessitar de mais espaço, utilize o verso e outras folhas. (MINISTÉRIO PÚBLICO FEDERAL, 2018).

Vale destacar que o refúgio é o último recurso que pode amparar os migrantes haitianos que, regularmente notificados ao ingressarem no território brasileiro, não tiveram êxito na sua regularização formal, permanecendo no país em condição jurídica precária e absolutamente desamparada, devendo, nesse caso, os pedidos de refúgio ter como fundamento grave violação dos direitos humanos, na forma tutelada pela Lei 9.474/97.

Ainda que o CONARE não tenha acatado os pedidos de refúgio dos migrantes haitianos até o presente momento, a situação excepcional ocasionada pela pandemia mundial do COVID-19 fez surgir uma possível tábua de salvação, consistente no importante precedente 
judicial que, em sede liminar, determinou a proibição de deportações de migrantes em situação de vulnerabilidade, bem como obrigou o Brasil a acatar todos os pedidos de refúgio e residência durante a pandemia do COVID-19. Embora referida decisão seja provisória e pontual, valendo apenas para o caso concreto vivenciado nas fronteiras do Estado do Acre, abrangendo em sua maioria migrantes venezuelanos, se trata de precedente que pode conduzir a outras decisões judiciais nas demais fronteiras do país e que poderá abranger outras nacionalidades de migrantes vulneráveis.

Em 19 de agosto de 2020, a organização não governamental Conectas Direitos Humanos veiculou notícia no seu sítio da rede mundial de computadores, sobre a decisão liminar proferida pela Justiça Federal do Acre no Processo n. 1004501-35.2020.4.01.3000), cuja fundamentação e dispositivo final ratificou o espírito inclusivo da legislação brasileira que tutela as migrações internacionais:

"Decido.

Tendo em vista o risco de perecimento de direito, ante a expedição de novos termos de deportação de outro grupo de 5 estrangeiros, passo ao exame do pedido de tutela de urgência, antes do transcurso do prazo concedido para a manifestação preliminar da União. Os documentos que instruem a inicial, em especial os termos de declaração dos imigrantes, laudos médicos, despacho da Diretoria do Departamento de Migrações do Ministério da Justiça e Segurança Pública e os registros fotográficos corroboram, ao menos em parte, os fatos narrados pelos autores. Em relação ao grupo objeto da ação 100433248.2020.4.01.3000, por exemplo, foram comprovados: a nacionalidade estrangeira (em sua maioria da Venezuela); as precárias circunstâncias do ingresso no Brasil (parte do trajeto foi percorrida a pé); os motivos do abandono do país de origem e do Peru (condições adversas em que viviam) e a presença de pessoas vulneráveis. Ainda segundo a informação policial, referida na decisão proferida naqueles autos, "todos os imigrantes, juntamente com os que já se encontram no local, ficaram sobre a ponte sem local para dormir, sem recursos e na incerteza sobre a sua alimentação nos próximos dias". Essa realidade se repete, de forma mais ou menos semelhante, em relação a outros grupos de imigrantes. Por se tratar de fato público e notório, desnecessária maior digressão sobre as graves violações das liberdades praticadas na Venezuela, país de origem da maioria dos integrantes do grupo. Esse contexto fático revela que os migrantes tentavam fugir de condições de vida pretéritas opressivas e insustentáveis, buscando no Brasil um futuro melhor, com maior liberdade e bem-estar. A despeito da validade prima facie da regra que proíbe o ingresso de estrangeiro durante a pandemia, as circunstâncias acima descritas indicam elevada probabilidade de que sua aplicação a casos semelhantes aos descritos resultaria em severo risco à vida, à saúde e à integridade de pessoas aparentemente refugiadas, sendo parte delas formada por mulheres, 
grávidas, crianças e adolescentes. Ademais, a aplicação da Portaria Interministerial a caso dessa natureza implicaria grave violação de hipóteses normativas de hierarquia superior. De fato, ao fixar as diretrizes da política migratória brasileira, o art. $3^{\circ}$ da Lei 13.445/2017 (Lei de Migração) proíbe a prática de expulsão ou deportação coletivas, como no caso, além de prestigiar a acolhida humanitária e proteção integral ao interesse da criança e do adolescente. Por sua vez, o art. $7^{\circ}, \S 1^{\circ}$, da Lei 9.474/97 (Lei do Refúgio) prevê que, em hipótese alguma, será efetuada a deportação do refugiado para fronteira de território em que sua vida ou liberdade esteja ameaçada, em virtude de raça, religião, nacionalidade, grupo social ou opinião política. Nessa seara, convém lembrar a proibição de reentrada dos estrangeiros no país vizinho. Por fim, como também destacado pela Defensoria, o art. $8^{\circ}$ da Lei $9.474 / 1997$ estabelece que o ingresso irregular no território nacional não constitui impedimento para 0 estrangeiro solicitar refúgio às autoridades competentes.

Com essas razões, defiro parcialmente a tutela de urgência para suspender os atos de deportação, repatriação ou outra medida compulsória de saída de estrangeiros em condição de vulnerabilidade, interessados em obter acolhida humanitária ou refúgio no Brasil, devendo a União assegurar-lhes o direito de requerer administrativamente o reconhecimento da condição de refugiado. Esclareço que as medidas de urgência deferidas não obstam (na realidade, obrigam) a adoção, pela União, dos protocolos relacionados à pandemia do coronavírus compatíveis. Remetam-se os autos ao Núcleo de Conciliação, para realização da audiência." (grifos intencionais)

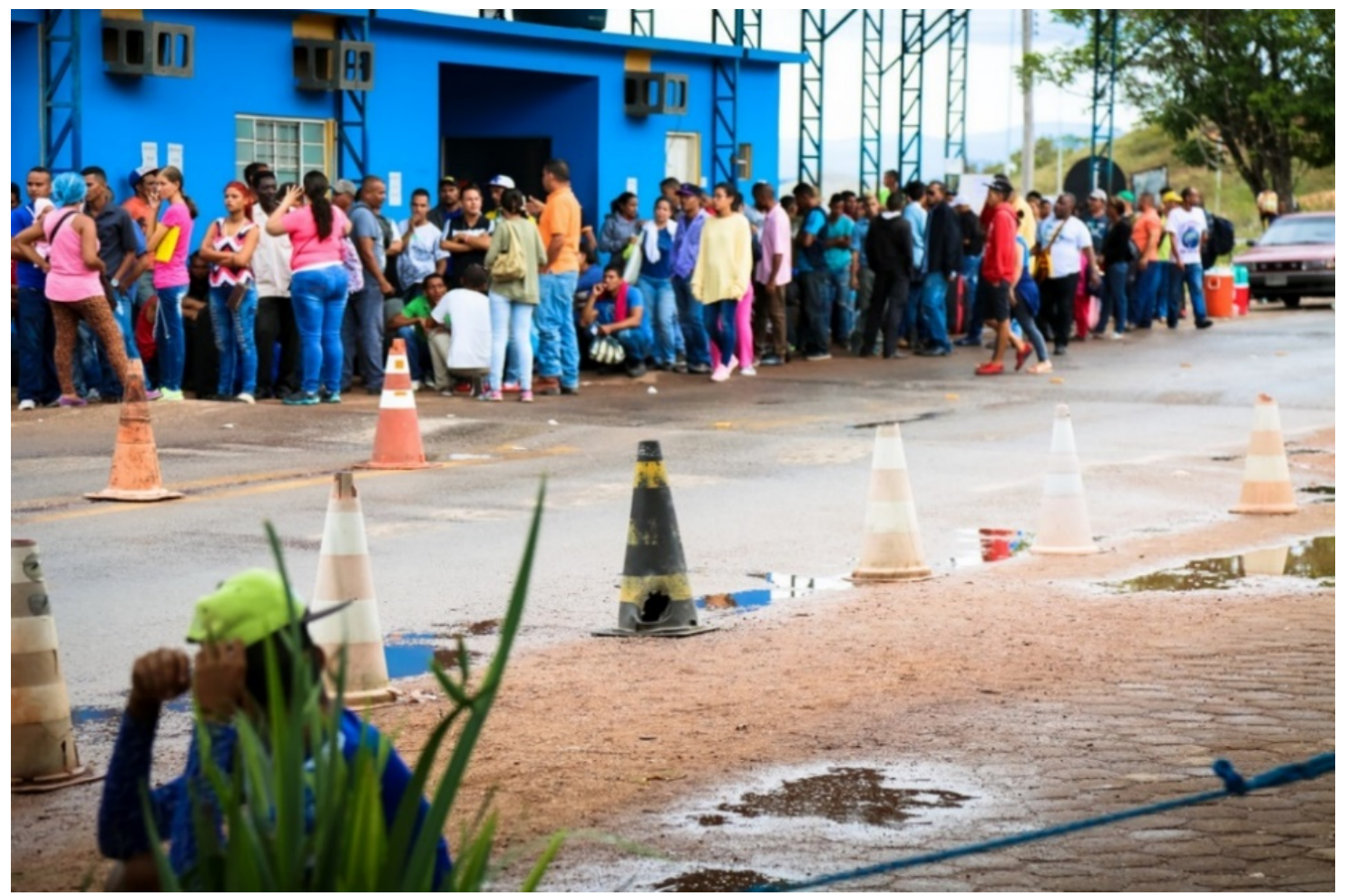

Figura 1: Fila no posto de fronteira da Polícia Federal na cidade de Pacaraima (RR) para 
registrar a entrada no país. Fonte: Conectas Direitos Humanos, 2020.

Migrantes venezuelanos fazem fila no posto de fronteira da Polícia Federal na cidade de Pacaraima (RR) para registrar a entrada no país (Foto: Leona...

A Justiça Federal do Acre decidiu liminarmente nesta quarta-feira (19) impedir o governo brasileiro de deportar ou repatriar migrantes vulneráveis que cheguem às fronteiras e obrigou o país a aceitar pedidos de refúgio e de residência durante a pandemia de Covid-19.

A atual portaria interministerial sobre fronteiras proíbe a entrada de migrantes por via terrestre e aquaviária e estabelece que aqueles que tenham ainda assim entrado no país sejam impedidos de pedir refúgio.

A decisão da Justiça é uma resposta a uma Ação Civil Pública movida pela DPU (Defensoria Pública da União), Ministério Público Federal, Conectas Direitos Humanos e Cáritas Arquidiocesana de São Paulo. De acordo com as entidades, a portaria viola a Lei de Refúgio, a Lei de Migração e uma série de compromissos internacionais assumidos pelo Brasil em matéria de migração. (Fonte: CONECTAS DIREITOS HUMANOS, 2020.)

Referida decisão judicial, ainda que em sede provisória, enfrentou questões sensíveis que interferem diretamente na atual política migratória brasileira, obrigando o governo brasileiro a fiel observância da Lei de Migração e garantindo a dignidade dos migrantes internacionais que se encontrem no território nacional, acendendo uma luz de esperança aos imigrantes haitianos que poderão utilizar tal precedente como paradigma para fundamentar o reconhecimento judicial da sua condição de refugiados.

\section{Conclusão}

Conclui-se que o Brasil possui em sua história período considerável de restrições e preconceitos no controle de entrada de migrantes internacionais, demonstrando um real interesse na busca de mão de obra barata de imigrantes vulneráveis e com padrões definidos por eugenia, antissemitismo camuflado, dentre outras restrições, tratando o migrante como estrangeiro que representava potencial ameaça à soberania e segurança nacional.

Embora a nova lei de migração tenha em seu texto sepultado definitivamente os critérios obscuros de controle de migração que por décadas conduziram a política migratória do governo brasileiro, deflagrando uma nova fase de desenvolvimento de políticas públicas voltadas para a garantia dos direitos humanos fundamentais do migrante internacional, em especial nos setores da saúde, assistência social e educação, não há como deixar de registrar o descompasso ainda existente entre a política migratória empreendida pelo atual governo federal e as garantias referidas pela novel legislação que tutela as migrações. 
A ação civil pública movida pela Defensoria Pública da União em conjunto com o Ministério Público Federal, Conectas Direitos Humanos e Cáritas Arquidiocesana de São Paulo, acima referida, retrata o descompasso ainda existente entre a política migratória praticada pelo governo brasileiro e a legislação inclusiva vigente no país, cujos resquícios de décadas de restrições preconceituosas ainda se fazem presentes, expondo a necessidade da intervenção do judiciário federal brasileiro para garantir os direitos fundamentais dos migrantes internacionais vulneráveis que se encontram em território nacional.

D’outra banda, a decisão judicial proferida pela Justiça Federal brasileira, ainda que em sede liminar e, portanto, provisória, servirá como precedente paradigma para reacender as esperanças dos migrantes haitianos e de outras nacionalidades em obter o reconhecimento da condição de refugiados, com fundamento na Lei de Migração no 9.474/97, que em seu art. 1 으, inciso III passou a prever o reconhecimento da condição de refugiado com base na grave e generalizada violação de direitos humanos.

\section{Referências}

AMARAL, Antonio Carlos Rodrigues. Tratados internacionais na ordem jurídica brasileira. São Paulo: Aduaneiras, 2007.

BARROSO, L. R.. O Direito Constitucional e a Efetividade de suas Normas. Rio de Janeiro: Renovar, 2001.

BARROSO, L. R. Interpretação e aplicação da constituição. São Paulo: Saraiva, 2003.

BOBBIO, Norberto. A era dos direitos. Rio de Janeiro: Editora Campus, 1992.

BRASIL. Decreto n. 1.641, de 7 de janeiro de 1907. Define providências sobre a expulsão de estrangeiros do território nacional. Rio de janeiro, RJ, Jan 1907.

BRASIL. Decreto n. 2.741, de 8 de janeiro de 1913. Revoga os arts. $3^{\circ}$ e $4^{\circ}$, parágrafo único, e $8^{\circ}$ do Decreto n. 1.641, de 7 de janeiro de 1907. Rio de Janeiro, RJ, Jan 1913.

BRASIL. Decreto-Lei n. 406, de 4 de maio de 1938. Dispõe sobre a entrada de estrangeiro no território nacional. Rio de janeiro, RJ, mai 1938.

BRASIL. Decreto n. 50.215, de 28 de janeiro de 1961. Promulga a convenção relativa ao estatuto dos refugiados de 1951. Brasília, DF, jan 1961.

BRASIL. Decreto n. 70.946, de 7 de agosto de 1972. Promulga o protocolo sobre o estatuto dos refugiados. Brasília, DF, ago 1972 
BRASIL. Lei n. 6.815, de 19 de agosto de 1980. Define a situação jurídica do estrangeiro no Brasil, cria o Conselho Nacional de Imigração. Brasília, DF, ago 1980.

BRASIL. Lei n. 9.474, de 22 de julho de 1997. Define mecanismos para a implementação do Estatuto dos Refugiados de 1951. Brasília, DF, jul 1997.

BRASIL. Lei n. 13.445, de 24 de maio de 2017. Institui a Lei de Migração. Brasília, DF. mai 2017.

BRASIL, Lei 13.684, de 21 de junho de 2018. Dispõe sobre medidas de assistência emergencial para acolhimento a pessoas em situação de vulnerabilidade decorrente de fluxo migratório provocado por crise humanitária; e dá outras providências. Brasília, DF, jun 2018.

BRASIL. Portaria Interministerial $\mathbf{n}^{0}$ 10, de 06 de abril de 2018. Dispõe sobre a concessão do visto temporário e da autorização de residência para fins de acolhida humanitária para cidadãos haitianos e apátridas residentes na República do Haiti. Brasília, DF, abr 2018.

BRASIL. Assembleia Constituinte (1988). Constituição Federativa do Brasil. Brasília: Senado Federal, 2020.

BRASIL. Resolução no 145/04 - Política Nacional de Assistência Social (PNAS). Disponível em:

http://www.mds.gov.br/sobreoministerio/legislacao/assistenciasocial/resolucoes/2004/Resoluc ão CNA Acesso em: 03 set. 2018.

BRASIL. Resolução no 130/05 - Norma Operacional Básica (NOB/SUAS). Disponível em: http://www.mds.gov.br/sobreoministerio/legislacao/assistenciasocial/resolucoes/2005/Resuca o CNA Acesso em: 03 Set. 2018.

BRASIL. Resolução no 109/09 - Tipificação Nacional de Serviços Socioassistenciais. Disponível em:

http://www.mds.gov.br/sobreoministerio/legislacao/assistenciasocial/resolucoes/2009/Resoluc ao CNA Acesso em: 03 Set. 2018.

CARNEIRO, Maria Luiza Tucci. Cidadão do Mundo: o Brasil diante do holocausto e dos judeus refugiados do nazifascismo (1933-1948). São Paulo: Ed. Perspectiva Fapesp. 2010.

CARVAlHO FILHO, J. dos S. Manual de Direito Administrativo. São Paulo: Ed. Atlas. 2018.

COMPARATO, Fabio Konder. A Afirmação Histórica dos Direitos Humanos. São Paulo: Saraiva, 2007.

D’AngelO, E. Administração Municipal e Política Administrativa. São Paulo: Ed. Anhanguera, 2015.

DEL VECCHIO, Giorgio. Teoria do Estado. Barcelona: Editora Bosch, 1956.

GENTILLI, R. de M. L. Representações e práticas: identidade e processos de trabalho no serviço social. São Paulo: Veras, 2006. 
GIL, A. C. Métodos e técnicas de pesquisa social. 5. ed. São Paulo: Atlas, 1999.

GUERRA, Sidney. Curso de Direito Internacional Público. São Paulo: Saraiva, 2017.

HATHAWAY, James C. The Law of Refuge Status. Toronto, Butterworths, 1991.

JUBILUT, Liliana Lyra. O direito internacional dos refugiados e sua aplicação no ordenamento jurídico brasileiro. São Paulo: Editora Método, 2007.

CONECTAS. Justiça Federal Barra Deportação de Migrantes Vulneráveis na Pandemia. Disponível em: https://www.conectas.org/noticias/justica-federal-barra-deportacao-demigrantes-vulneraveis-na-pandemia.> Acesso em 2020.

KINCHESCKI, Cristiano. A supraconstitucionalidade dos tratados internacionais de direitos humanos fundamentais. Brasília-DF: OAB Editora, 2006.

KOIFMAN, Fábio. Imigrante Ideal. Rio de Janeiro. Editora Civilização Brasileira, 2012.

MALUF, A. Direito de Família:Teoria e Prática. São Paulo. Ed. Anhanguera, 2010.

MARTINS, Flavio. Curso de Direito Constitucional. São Paulo: Saraiva, 2019.

MAZZUOLI, Valério de Oliveira. Tratados internacionais. São Paulo: Juarez de Oliveira, 2007.

Curso de direito internacional público. São Paulo: Saraiva, 2018.

NETTO, J. P. Crise do Socialismo e Ofensiva Neoliberal. São Paulo: Cortez, 1993.

PIOVESAN, Flávia. Direitos humanos e justiça internacional. São Paulo: Saraiva, 2017. 2012 .

Direitos humanos e o direito constitucional internacional. São Paulo: Saraiva,

ROTHEMBURG, W.C.,. BONAVIDES, P.; MIRANDA, J.; AGRA, W. de M (coord.).

Comentários à Constituição Federal de 1988. Rio de Janeiro: Forense, 2009.

SCHIER, Adriana da Costa Ricardo. Serviço Público: Garantia Fundamental e Cláusula de Proibição de Retrocesso Social. Curitiba. Editora Íthala, 2019.

SECCHI, Leonardo. Políticas Públicas: Conceitos, esquemas de análise, casos práticos. São Paulo. Cengage Learning. 2010.

TRINDADE, Antonio Augusto Cancado. A humanização do direito internacional. Belo Horizonte. Del Rey, 2007. 
